\title{
Distance education during social isolation: an evaluation of student attitudes and perceptions using the web-based learning environment instrument (WEBLEI)
}

\author{
İsmet Demirtaş (D), Sevilay Ayyıldız (D), Behçet Ayyıldız (D), Koral Çağlar Kuş (iD \\ Department of Anatomy, Faculty of Medicine, İstinye University, Istanbul, Turkey
}

\begin{abstract}
Objectives: Until recently, distance education at universities has supplemented face-to-face education in blended programs that combine the two. But during the COVID-19 pandemic in the spring of the 2019-2020 academic year, many universities were forced to conduct distance education exclusively. The aim of this study is to determine the perceptions, thoughts, and experiences of university students regarding the completely online process of distance education during this period.

Methods: In this process, all theoretical lessons and exams were conducted on the advance learning management system (ALMS) for distance education at Istinye University. The present study used the original form of WEBLEl to survey 324 students from medicine, pharmacy and health science departments at Istinye University.

Results: WEBLEl measures students' perceptions using four scales: access, interaction, response and results. Though students did not experience problems accessing online lessons or interacting with their teachers and other students, they did not find online distance education alone more effective and satisfying than combined with face-to-face education.
\end{abstract}

Conclusion: This study contributes to a better understanding of the pros and cons of distance education by evaluating the attitudes and perceptions of university students.

Keywords: distance education; online lessons; social isolation; WEBLEl; web-based learning

Anatomy 2021;15(2):163-170 C2021 Turkish Society of Anatomy and Clinical Anatomy (TSACA)

\section{Introduction}

Distance education is an educational method that does not require students to attend school lessons physically. ${ }^{[1]}$ It may be seen in hybrid (blended) programs that combine online education courses with face-to-face education courses or it may appear alone as online education courses. ${ }^{[2]}$ Web-based learning is defined as a form of distance education which uses computer and internet technology.

Universities prefer distance education more commonly than in the past, but there are still conflicts about distance education at universities, and educators have some doubts about its effectiveness. ${ }^{[4]}$ Many studies have shown the benefits of distance education for both schools and students. Singh $^{[5]}$ remarked that hybrid lessons offer stu- dents better learning experiences and are more effective than classroom-based lessons alone. Young ${ }^{[6]}$ supported the idea that offering various materials to students maximizes student engagement since not all students learn in the same way. A study at the University of Wisconsin (Milwaukee, WI, USA) showed that students learn better in hybrid education programs compared to face-to-face education alone. Teachers responsible for the hybrid education program at the university reported that students wrote better papers, got higher marks, produced more quality projects, and discussed lessons more meaningfully. ${ }^{[7]}$ Dantas and Kemm ${ }^{[8]}$ showed a high positive correlation between distance education lessons and students' final exam results. Joynes and Fuller ${ }^{[9]}$ remarked that distance education, with the advancement of technology, allows 
students to attend classes from anywhere with an internet connection. Kirtman ${ }^{[10]}$ maintained that distance education offers students opportunities that face-to-face education cannot offer, stating that distance education enables students to listen again to what they could not understand well during the lesson. Distance education also benefits universities. The hybrid education may enable universities to reduce the number of overcrowded classes, which allows universities to make more classes available even at peak demand times of the day. ${ }^{[1]}$

Despite its advantages, distance education has its critics. Students may lack adequate technologic infrastructure and proper training to use a distance education system correctly, which may cause them bad experiences in the distance education process. ${ }^{[12]}$ One study has argued that social isolation during the distance education process and lack of social interaction reduces the educational success of students and prevents them from developing socially. ${ }^{[5]}$ Green and Whitburn ${ }^{[13]}$ stated that faceto-face education is of a higher quality than distance education, particularly in terms of experimental learning, and indicated that students do not value distance education as much as face-to-face education. Courses offered only online were not perceived by students to be as successful as face-to-face courses. ${ }^{[14,15]}$

SARS-Cov-2 is a coronavirus that causes a severe acute respiratory syndrome in humans. It was first identified in December 2019 in China and thereafter spread rapidly to other countries. ${ }^{[16,17]}$ The World Health Organization (WHO) declared COVID-19 infections worldwide a pandemic in March 2020, forcing governments across the world to take precautions against the further spread of the disease; one such precaution was to close university campuses, and many universities elected to continue to their courses online.

Though many studies have shown the benefits of distance education, deficiencies are also clearly visible and these increase the pandemic anxiety of university students. ${ }^{[18.19]}$ This study aims to determine students' attitudes and perceptions regarding lessons delivered via distance education in the pandemic period. We surveyed medicine, physiotherapy/rehabilitation, nutrition/dietetics, and pharmacy students because of the prevalence of practical lessons in their syllabi and the many practical lessons these students missed. Our study included a total of 324 students enrolled at İstinye University who participated in distance education during the pandemic. All participants completed the web-based learning environment instrument (WEBLEI).

\section{Materials and Methods}

The literature contains studies that evaluate and compare the advantages and disadvantages of distance education to those of face-to-face education using various surveys. After reviewing the literature, the researchers decided to use the WEBLEI for this study. Developed by Chang and Fisher, ${ }^{[20]}$ the WEBLEI is a multidimensional construct that assesses student perceptions of four core aspects of the Web-based learning environment: access, interaction, response and results. After obtaining permission from the survey owner, our study used the survey to evaluate student attitudes and perceptions of distance education during the pandemic.

A total of 324 students (231 female, 93 male) at İstinye University from the departments of medicine, pharmacy and health science participated in the study. The departments of the students participating in the study are shown in Table 1.

The survey was sent to first- and second-year students in health-related departments; departments providing instruction in English were preferred. Participation in the study was voluntary. Participation rates in the courses was not considered because students could take courses online or offline using the ALMS platform. The demographic characteristics of the students are presented in Table 2.

At İstinye University, all theoretical lessons and exams that could not be conducted face-to-face in the spring of 2020 due to the COVID-19 pandemic were given online via the advanced learning management system (ALMS) for distance education. In this process, the distance education system implemented the content of the face-to-face education lessons. Study participants received online lessons through the "ALMS" and "Perculus plus" software systems. For online lessons, students and lecturers needed a computer, tablet, or mobile devices with camera features. The duration of each lesson was limited to a maximum of 50 minutes. A message ('chat') box on the lesson screen permits students to share their questions or problems with lecturers and other students. Online lessons are

Table 1

Distribution of students according to their departments.

\begin{tabular}{lc} 
Faculty/Department & Frequency \\
\hline Faculty of Medicine & 55 \\
\hline Faculty of Pharmacy & 154 \\
\hline $\begin{array}{l}\text { Faculty of Health Sciences / Department of Physiotherapy } \\
\text { and Rehabilitation }\end{array}$ & 92 \\
\hline $\begin{array}{l}\text { Faculty of Health Sciences / Department of Nutrition } \\
\text { and Dietetics }\end{array}$ & 23 \\
\hline Total & 324 \\
\hline
\end{tabular}


Table 2

Frequencies and relative percentages of demographic characteristics.

\begin{tabular}{|c|c|c|c|c|c|}
\hline \multirow{2}{*}{\multicolumn{2}{|c|}{ Demographic Characteristics }} & \multicolumn{4}{|c|}{ Frequency } \\
\hline & & \multirow{2}{*}{$\begin{array}{c}\text { Faculty of Medicine } \\
38\end{array}$} & \multirow{2}{*}{$\begin{array}{c}\text { Faculty of Pharmacy } \\
104\end{array}$} & \multirow{2}{*}{$\begin{array}{c}\text { Department of Physiotherapy } \\
\text { and Rehabilitation }\end{array}$} & \multirow{2}{*}{$\begin{array}{c}\begin{array}{c}\text { Department of Nutrition } \\
\text { and Dietetics }\end{array} \\
23\end{array}$} \\
\hline Gender & Female & & & & \\
\hline & Male & 17 & 50 & 26 & - \\
\hline \multirow[t]{2}{*}{ Age (in years) } & $18-22$ & 52 & 137 & 84 & 22 \\
\hline & $23-26$ & 3 & 17 & 8 & 1 \\
\hline \multirow[t]{2}{*}{ Grade } & $1 s t$ & 46 & 146 & 56 & 15 \\
\hline & 2nd & 9 & 8 & 36 & 8 \\
\hline
\end{tabular}

automatically recorded and later published, so students can watch them after the lesson concludes.

For the purposes of the study, survey questions were uploaded to the Internet via Google Forms. The candidates consented in writing to participate in the study before beginning the survey. After giving their approval, they were allowed to access the survey questions via a link to the web page containing the questionnaire. After the distance education program was implemented for the COVID-19 period, the survey was conducted from 22.07.2020 to 29.07.2020.

This study used the WEBLEI ${ }^{[20]}$ to collect data on student perceptions of their web-based learning experience. The WEBLEI measures student perceptions along four scales: access, interaction, response, and results. All four scales include necessary components for student success in a teaching and learning environment. In this study, WEBLEI scales were unchanged and used in their original forms.

The WEBLEI survey contains a total of 32 items, with eight items along each scale. The answers to the items in the scales include: almost always (5), often (4), sometimes (3), seldom (2), and almost never (1). The 'access' scale measures the accessibility of the learning environment to students; this scale aims to learn how well students adapt to their learning environment. The 'interaction' scale investigates how beneficial students judge distance education to be; through this scale, students evaluate the quality of the interactions amidst their classmates, lecturers, and themselves. The 'response' scale indicates how students feel and think about the web-based learning system. The 'results' scale expresses the extent to which students believe they accomplished any of the learning objectives within the online learning environment. ${ }^{[19-21]}$

The data was analyzed using Statistical Package for Social Sciences (SPSS Version 24, Armonk; NY, USA). A parametric Student's t-test compared two independent groups of students, and parametric ANOVA test compared more than 2 groups. Bonferroni was used as the post-hoc test. Quantitative data was expressed in the tables as mean \pm standard deviation and median (minimum-maximum) values, and categorical data was expressed in $\mathrm{n}$ (number) and percentages (\%). The data was analyzed in the $95 \%$ confidence interval, p-value was considered as significant if less than 0.05 .

\section{Results}

Results of the study have been presented using the scales and items of WEBLEI. The WEBLEI contains four main scales, each including eight questions. Students' emotions, experiences, and thoughts about the accessibility of distance education lessons, the interaction between students and teachers during the distance education period and the process of the distance education method were obtained through the questionnaire items. The participants were students in the health sciences departments at İstinye University and all completed the questionnaire in its entirety. Participants' answers were evaluated without regard to their different faculties. Means of 3.32, 3.37, 2.75 and 3.00 were obtained for access, interaction, response, and results scales (Table 3). Questionnaire items and results of the scales are shown in Table 4.

Table 3

Weighted means, median and standard deviation for the four scales of the WEBLEI

\begin{tabular}{lccc} 
WEBLEI scales & Mean & Median & Standard deviation \\
\hline Scale I- Access & 3.32 & 3.50 & 1.02 \\
\hline Scale II- Interaction & 3.31 & 3.37 & 0.93 \\
\hline Scale III- Response & 2.75 & 2.62 & 1.04 \\
\hline Scale IV- Results & 3.00 & 3.00 & 1.07 \\
\hline
\end{tabular}




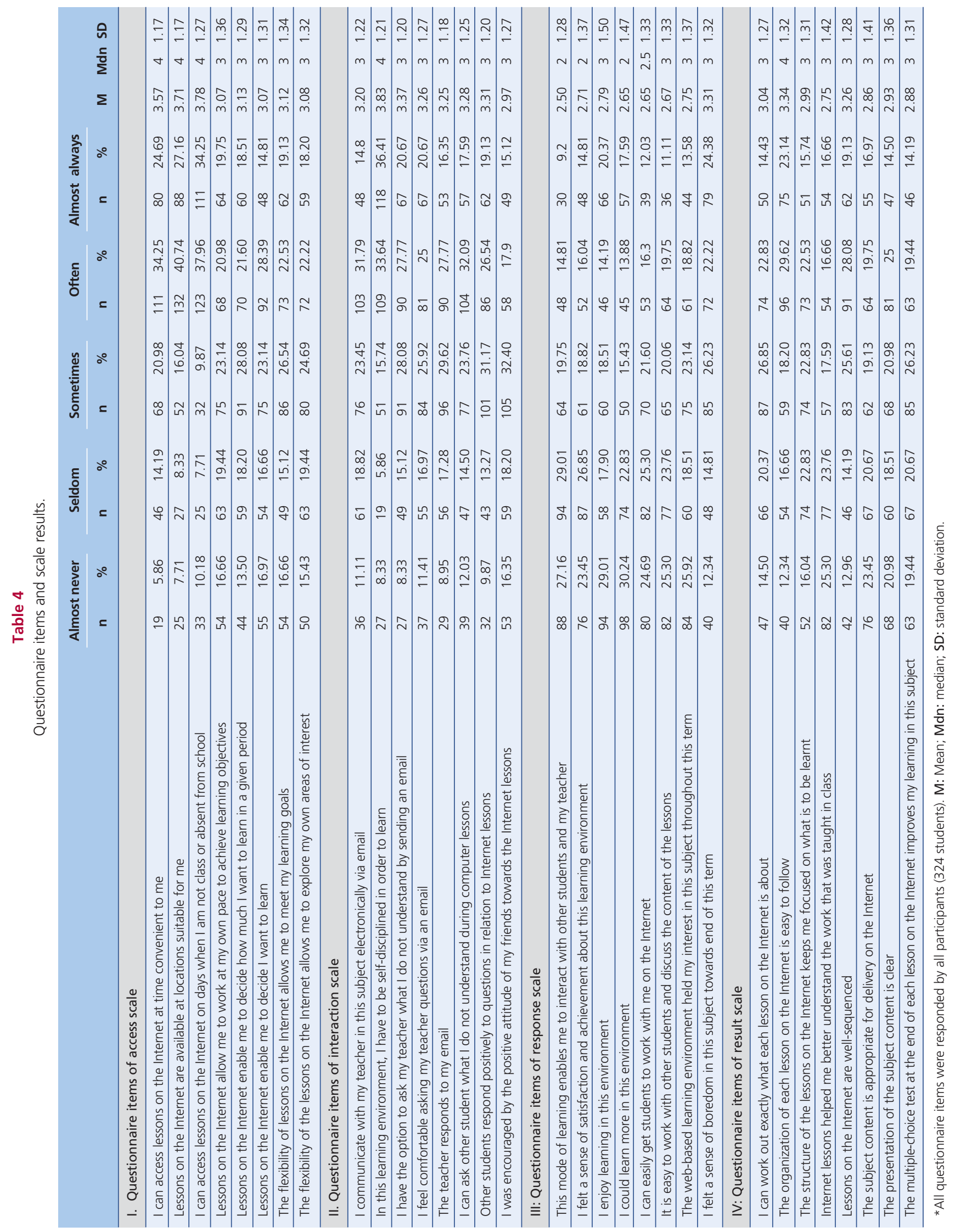


The first scale of this questionnaire concerns accessibility of distance education lessons via internet connection. This scale evaluated the convenience of online lesson times and locations for students and the effects of online lesson flexibility on students' learning processes. Many participants remarked that online lessons permitted access at any time ( $M=3.57)$ and any location $(M=3.71)$. The access scale suggested that the online learning environment allows access to lessons even when students are not in class or absent from school $(M=3.78)$. However, percentage about students deciding how much they learn and what they learn on the online lessons is close to each other. Moreover, the answers regarding the flexibility of the lessons on the internet for the realization of learning goals and the exploration of their own interests were close to each other. The median response to questions related to contribution of online courses to student learning goals and achievements was 3 . While some students agreed that these lessons met their learning goals and allowed them to explore their areas of interest, some of them have strongly disagreed. As a result, not all the students shared the same idea about their educational attainment. In a comparison of departments, statistically significant differences were seen between Physiotherapy/Rehabilitation $(M=2.91)$ and Medicine $(M=3.75) /$ Pharmacy $(M=3.37) /$ Nutrition $(M=$ 3.44) $(\mathrm{p}<0.001)$.

The interaction scale is associated with the student experience of communication within distance education. Participants indicated that they often contacted their teachers electronically via email $(M=3.20)$. There are other platforms where students communicate with their teachers besides e-mail, but the interaction scale specifically asks about communication established via e-mail. Students stated that they were able to communicate with their teachers easily and conveniently via e-mail. Further, they remarked that their teachers sometimes responded to their emails $(M=3.25)$. Participants liked email as a means of communicating about lesson content they did not understand, and they generally felt comfortable asking their teachers questions via email $(M=3.26)$. A high percentage of the students chose 'often' and 'sometimes' options regarding their communication with other students. The majority of students thought they could ask other students questions during online lessons $(M=3.28)$; some students responded positively to questions in relating to online lessons $(M=3.31)$. Further, the majority of students indicated that self-discipline was necessary in the online learning environment ( $M=3.28)$.

The response scale posed questions relating to student satisfaction in the online learning environment. A high percentage of the participants did not think that the online learning model allows them to interact, work and discuss the content of the lessons with other students. Furthermore, the majority of participants had negative impressions of learning in this environment. The majority of them replied they 'almost never' enjoyed learning in this environment $(M=2.79)$. Likewise, students thought they could not learn more in this environment $(M=2.65)$ and many did not feel a sense of satisfaction or achievement in this learning environment $(M=2.71)$. They indicated that they found this education model boring $(M=3.31)$ and the online learning environment did not hold their interest in throughout this term $(M=2.75)$. Statistical analysis showed that the mean answer for the second-grade students $(M=2.44)$ is significantly lower than the first-grade students $(M=2.83)$ in this scale $(\mathrm{p}=0.009)$.

The result scale, the last part of the questionnaire, included questions about the organization and content of the lessons on the internet. Study results indicated the participants believed they could sometimes figure out completely what each lesson online was about $(M=3.04)$. While the organization of each lesson online was easily followed by many participants ( $M=3.34)$, the majority did not think that lessons online helped them understand the subject better than lessons in the classroom $(M=2.75)$. In addition, the students did not all share the opinion that online lessons kept them focused. When asked about content presentation, a high percentage of the students thought that content was not appropriate to online delivery $(M=2.86)$. Many participants stated that course content and presentation of information were not effectively delivered online $(M=2.93)$. In the distance education program, multiple-choice tests and other types of exams were given to students at the end of each lesson or at the end of the term. The lowest percentage of the participants believed that multiple-choice tests at the end of each lesson online always facilitated learning, but the highest percentage of the participants believed that multiple-choice tests at the end of each lesson online 'sometimes' facilitated learning $(M=2.88)$. In this scale, there were statistically significant differences among departments, gender, and grades. Statistically significant differences were seen in comparing the Physiotherapy/Rehabilitation departments $(M=2.58)$ and both Medicine $(M=3.46)$ / Pharmacy $(M=3.07) /$ Nutrition $(M=3.17)$ departments $(p<0.001)$. The average mean for the female students $(M=3.11)$ is significantly higher than the male students $(M=2.76)$ along this scale $(\mathrm{p}=0.008)$; and the mean for the secondgrade students $(M=2.56)$ is significantly lower than the first-grade students $(M=3.12)(\mathrm{p}<0.001)$. The results of all the scales are shown in Figure 1. 


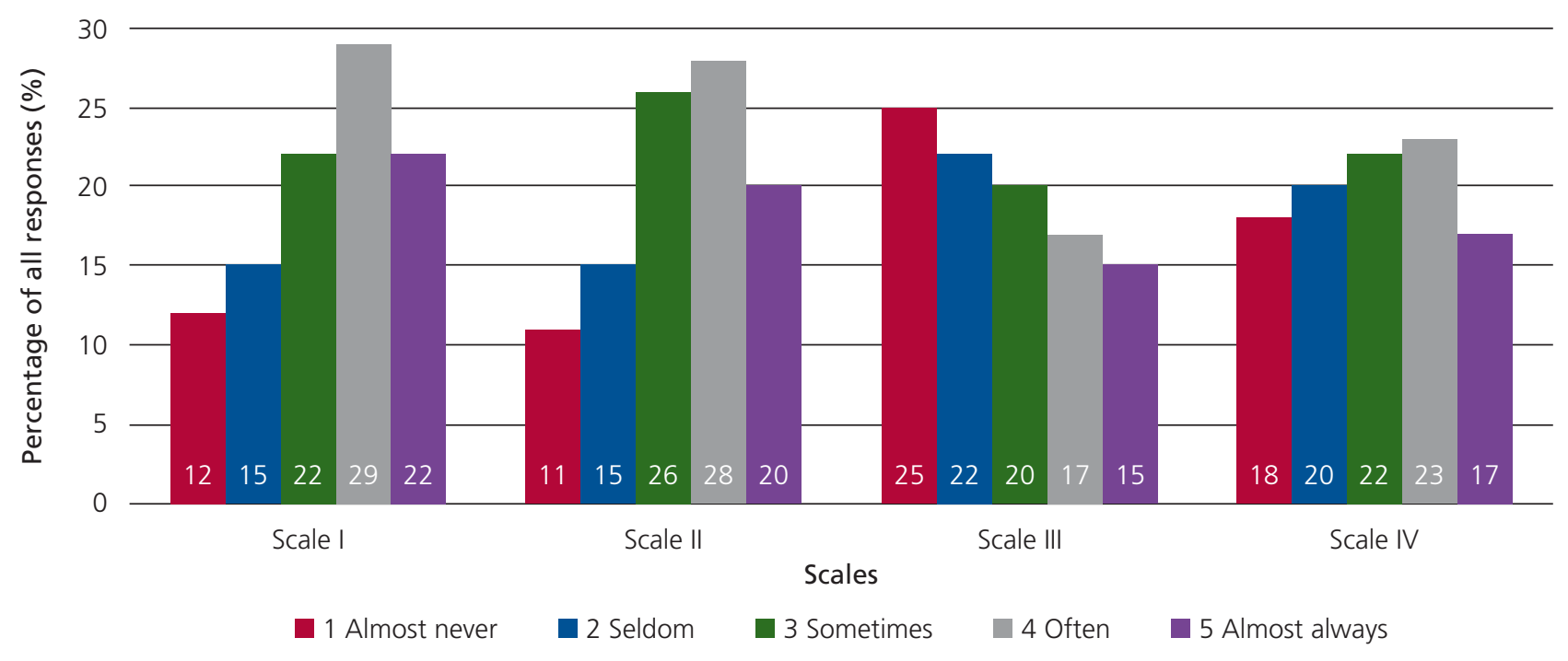

Figure 1. The four scales of the WEBLEl: student responses.

\section{Discussion}

The popularity of distance education has increased, especially in the undergraduate and postgraduate context. The COVID-19 pandemic has shown implementation of distance education to be accelerating and in need of focus. ${ }^{[2]]}$ This questionnaire study examines student perceptions about distance education during the COVID-19 pandemic.

Distance education has numerous undisputed advantages, including student access to lessons and course materials at any time with an internet connection. ${ }^{[4]}$ Joynes and Fuller ${ }^{[0]}$ remarked that distance education, with the advancement of technology, allows students to attend classes from anywhere with an internet connection. Sheryl et al. ${ }^{[2]}$ maintained that the learning environment was easily accessible in time and space for students. This study's access scale results support the findings of Sheryl et al. ${ }^{[2]}$ and Joynes and Fuller. ${ }^{[9]}$ Yet participants in this study had mixed views about the success of online lessons in helping them realize their learning goals and develop their interest areas. Although accessing lessons at any time and location offers clear advantages, distance education alone is not sufficient to meet the learning goals and interests of students. According to the significant differences seen in comparing the Physiotherapy/Rehabilitation and Medicine / Pharmacy fields along the access scale, it is possible to conclude that physiotherapy students have difficulty accessing their courses. It may be that these students had adaptation and motivation problems during the distance education period.

Students were able to contact with their teacher via communication options such as online chat, videoconfer- encing during class. When they needed to get in contact with their teacher for extracurricular questions during face-to-face education, they could ask them face-to-face; but students had only e-mail in the ALMS platform or personal e-mail accounts to access their teachers during distance education. WEBLEI's interaction scale (and the interaction scale of this study) specifically examines this method of communication between students and teachers. Dyrbye et al. ${ }^{[23]}$ has stated that lack of face-to-face communication between students and lecturers negatively affects the clarity of instructions and the quality of the feedback. Although they generally agreed that web-based learning gave them an opportunity to contact their teachers and other students, students stated that they did not completely feel comfortable communicating in this way. The interaction scale of other studies using WEBLEI showed similar results. ${ }^{[2]}$ Horzum $^{[24]}$ suggested that students who cannot adapt technologically to distance education have learning problems. Instructing both students and lecturers on how to interact on distance education platforms could positively affect student responses along the interaction scale.

The response scale included questionnaire items relating to student satisfaction surrounding the learning environment. In this study, the response scale was rated the lowest $(M=2.75)$. The results show the participants generally gave negative responses. Undergraduate students did not generally find web-based teaching in the COVID-19 pandemic period to be satisfactory and enjoyable; they did not feel successful during this learning period and did not find it easy to work with other students online. On the contrary, Ilahi et al. ${ }^{[25]}$ stated that postgraduate students were 
satisfied and enjoyed the learning process and working with other students in a blended learning environment. Chandra and Fisher ${ }^{[26]}$ revealed that students generally agreed that web-based learning was satisfactory. While Chandra and Fisher ${ }^{[26]}$ reported that the highest rating item for the response scale is "I enjoy learning in this environment" $(M=4.15)$, the rate is 2.79 for our study. The results showed that although students were generally satisfied in a blended learning environment, they were not satisfied when the education process was completely online and distanced. It can be concluded that although students like the fact that online learning is included along with face-to-face education, they are not satisfied taking all their lessons online. First and second-grade health-related faculties have course intensities and they have also theoretical and practical course differences. In our study, the scale mentioned above was used to question whether these factors affect the education model. Moreover, the weighted mean of first grade was significantly higher than the second grade in the response and result scale. Second-grade lessons were more intense than first-grade lessons in the health sciences departments. Thus, the weighted mean of first grade was significantly higher than the second grade in the response and result scales. All practical courses had to be conducted only on the ALMS platform, rather than in a laboratory or internship environment, so this situation may be due to student perception. Horzum ${ }^{[24]}$ stated that problems during the learning process can arise when practical lessons are conducted online. In our study, it is possible to report that second-grade students were not as satisfied as first-grade students with web-based learning due to the increasing intensity of their lessons, especially practical ones.

The results scale contains questions related to student perceptions about the structure, design, and content of the learning objectives. In this study, students stated generally that although they followed lessons easily and found the lessons well sequenced, they did not totally agree that the course content and presentation of information were best delivered online. This is dissimilar to other studies' findings that content and presentation of information were appropriate for distance education. ${ }^{[22]}$ The result scale's mean score for Physiotherapy/Rehabilitation is significantly lower than Medicine and Pharmacy, reflecting that physiotherapy students had difficulty adjusting to the distance education platform compared to the students in the other health faculties. In this study overall, the means of the four scales for the medicine students are the highest of all the departments. The reason for this significant difference is likely the motivation and adaptation of medical students and the academic staff during the pandemic period. Furthermore, future comprehensive studies are needed to address the comparisons between face-to-face and distance education with different methods in various departments due to differences in course intensity and contents among the departments.

\section{Conclusion}

The COVID-19 pandemic has forced universities to conduct the education through online platforms. Distance education has advantages and disadvantages and there are conflicts among educators and students regarding distance education. ${ }^{[4]}$ During the pandemic period, some pros and cons of distance education have been clearly realized. The COVID-19 pandemic period has shown that distance education platforms are needed and must continue to develop and evolve. This study identified student perceptions about distance education during the COVID-19 pandemic period and suggested that some aspects of distance education platforms need to improve. When online lessons are the only option, students should not be left thinking that online lessons are less effective and satisfying than face-to-face lessons. The COVID-19 pandemic period proved that educational institutions should always be prepared to conduct education using complete distancing.

\section{Conflict of Interest}

The authors declare that they have no competing interests.

\section{Author Contributions}

ID: manuscript writing/editing; SA: manuscript writing/ editing; BA: data collection and data analysis; ID: protocol/project development; KÇK: manuscript writing/editing; ID: data analysis.

\section{Ethics Approval}

Approved by İstinye University's Social and Human Sciences Research Ethics Committee, meeting number 2020/9 (decision number 05; date:20.07.2020).

\section{Funding}

This research received no specific grant from any funding agency in the public, commercial, or not-for-profit sectors.

\section{References}

1. Kaplan AM, Haenlein M. Higher education and the digital revolution: about MOOCs, SPOCs, social media, and the cookie monster. Business Horizons 2016;59:441-50.

2. Cleveland-Innes MF, Garrison DR. Introduction to distance education: understanding teaching and learning in a new era. New York: Routledge, Taylor \& Francis Group; 2010. p. 296.

3. Allen IE, Seaman J. Staying the course. Online education in the United States, 2008. Newburyport (MA): Sloan Consortium (NJ1); 2008. p. 28. 
4. Bernard RM, Brauer A, Abrami PC, Surkes M. The development of a questionnaire for predicting online learning achievement. Distance Education 2004:25:31-47.

5. Singh P. Unleashing the potential of ODL - reaching the unreached. Proceedings of the International Council for Open and Distance Education (ICDE) International Conference, 2017.

6. Young JR. "Hybrid" teaching seeks to end the divide between traditional and online instruction. Chronicle of Higher Education 2002; 48:33-4.

7. Lloyd-Smith L. Exploring the advantages of blended instruction at community colleges and technical schools. MERLOT Journal of Online Learning and Teaching 2010;6:508-15.

8. Dantas AM, Kemm RE. A blended approach to active learning in a physiology laboratory-based subject facilitated by an e-learning component. Adv Physiol Educ 2008;32:65-75.

9. Joynes V, Fuller R. Legitimisation, personalisation and maturation: using the experiences of a compulsory mobile curriculum to reconceptualise mobile learning. Med Teach 2016;38:621-7.

10. Kirtman L. Online versus in-class courses: an examination of differences in learning outcomes. Issues in Teacher Education 2009;18 $103-16$.

11. Gould T. Hybrid classes?: maximizing institutional resources and student learning. Proceedings of the 2003 Association Supporting Computer Uses in Education (ASCUE) Conference, 2003;54-9.

12. Distance learning task force 2007. Quality issues in distance learning. AACSB International-The Association to Advance Collegiate Schools of Business. [Internet]. [Retrieved on January 13, 2021]. Available from: https://numerons.files.wordpress.com/2012/04/16quality-issuesin-distance-learning.pdf

13. Green RA, Whitburn LY. Impact of introduction of blended learning in gross anatomy on student outcomes. Anat Sci Educ 2016;9: 422-30.

14. Mathiowetz V, Yu CH, Quake-Rapp C. Comparison of a gross anatomy laboratory to online anatomy software for teaching anatomy. Anat Sci Educ 2016;9:52-9.

15. Swinnerton BJ, Morris NP, Hotchkiss S, Pickering JD. The integration of an anatomy massive open online course (MOOC) into a medical anatomy curriculum. Anat Sci Educ 2017;10:53-67.

16. Lai CC, Shih TP, Ko WC, Tang HJ, Hsueh PR. Severe acute respiratory syndrome coronavirus 2 (SARS-CoV-2) and coronavirus disease-2019 (COVID-19): the epidemic and the challenges. Int J Antimicrob Agents 2020;55:105924.
17. Epidemiology Group of New Coronavirus Pneumonia Emergency Response Mechanism, Chinese Center for Disease Control and Prevention. The epidemiological characteristics of an outbreak of 2019 novel coronavirus diseases (COVID-19) in China. Zhonghua Liu Xing Bing Xue Za Zhi 2020;41:145-51.

18. Thomas E. Coronavirus: impact on young people with mental health needs. YoungMinds. Survey 2; 2020. [Internet]. [Retrieved on January 13, 2021]. Available from: https://www.youngminds.org.uk/media/ 355 gyqcd/coronavirus-report-summer-2020-final.pdf

19. Chandra V, Fisher D, Chang V. Investigating higher education and secondary school web-based learning environments using the WEBLEI. In: Le T, Le Q, editors. Technologies for enhancing pedagogy, engagement and empowerment in education: creating learning-friendly environments. Hershey (PA): IGI Global; 2011. p. 93-104.

20. Chang V, Fisher D. The validation and application of a new learning environment instrument for online learning in higher education. In Khine MS, Fisher D, editors. Technology-rich learning environments: a future perspective. River Edge (NJ): World Scientific Publishing Co. Pte. Ltd.; 2003. p. 1-20.

21. Klibanov OM, Dolder C, Anderson K, Kehr HA, Woods JA. Impact of distance education via interactive videoconferencing on students' course performance and satisfaction. Adv Physiol Educ 2018;42:215.

22. Sheryl A, Catura LS, Cruz JS Dela. E-learning effectiveness as inputs for a learning management system framework and policy. Asia Pacific Journal of Multidisciplinary Research 2019;7:112-7.

23. Dyrbye L, Cumyn A, Day H, Heflin M. A qualitative study of physicians' experiences with online learning in a masters degree program: Benefits, challenges, and proposed solutions. Med Teach 2009;31: 40-6.

24. Horzum MB. Sakarya Üniversitesi eğitim fakültesinde görev yapan öğretim elemanlarının internet destekli eğitime yönelik düşünceleri. Sakarya Üniversitesi Eğitim Fakültesi Dergisi 2003;0:246-62.

25. Ilahi CW, Rizky DAF, Wibawa AP, Nugraha E. Blended learning in postgraduate program. Proceedings of the 3rd International Conference on Science in Information Technology: theory and application of it for education, industry and society in big data era (ICSITECH), 2017;503-6.

26. Chandra V, Fisher DL. Assessing the effectiveness of a blended webbased learning environment in an Australian high school. In: Fisher D, Khine MS, editors. Contemporary approaches to research on learning environments: worldviews. Hackensack (NJ): World Scientific Publishing Co. Pte. Ltd.; 2006. p. 461-78.

Correspondence to: Ismet Demirtaş, PhD

Department of Anatomy, Faculty of Medicine, Istinye University,

Zeytinburnu, Istanbul, Turkey

Phone: +90 2124813688

e-mail: ismetdemirtas21@gmail.com

Conflict of interest statement: No conflicts declared.

This is an open access article distributed under the terms of the Creative Commons Attribution-NonCommercial-NoDerivs 4.0 Unported (CC BY-NCND4.0) Licence (http://creativecommons.org/licenses/by-nc-nd/4.0/) which permits unrestricted noncommercial use, distribution, and reproduction in any medium, provided the original work is properly cited. How to cite this article: Demirtaș İ, Ayyıldız S, Ayylldız B, Kuş KÇ. Distance education during social isolation: an evaluation of student attitudes and perceptions using the web-based learning environment instrument (WEBLEI). Anatomy 2021;15(2):163-170. 